\title{
HISTÓRICO, CARACTERIZAÇÃO E DINÂMICA RECENTE DO PRONAF - PROGRAMA NACIONAL DE FORTALECIMENTO DA AGRICULTURA FAMILIAR ${ }^{1}$
}

\section{HISTORY, CHARACTERIZATION AND RECENT DYNAMICS OF PRONAF - NATIONAL PROGRAM FOR STRENGTHENING FAMILY FARMING
HISTORIA, CARACTERIZACIÓN Y DINÁMICA RECIENTE DEL PRONAF - PROGRAMA NACIONAL PARA EL FORTALECIMIENTO DE LA AGRICULTURA FAMILIAR

\author{
Sergio Schneider ${ }^{2}$ \\ https://orcid.org/0000-0002-4353-6732 \\ Ademir Antonio Cazella ${ }^{3}$ \\ https://orcid.org/0000-0002-4457-4853 \\ Lauro Mattei ${ }^{4}$ \\ https://orcid.org/0000-0002-1270-8052
}

Submetido: 14/07/2020 / Aceito: 03/08/2020.

\begin{abstract}
RESUMO
Nesse artigo discutiu-se a importância e a trajetória do Programa Nacional de Fortalecimento da Agricultura Familiar (Pronaf), criado no ano de 1996. Após fazer uma breve discussão sobre o processo histórico de lutas das organizações dos trabalhadores rurais em prol de uma política agrícola específica para esse segmento social, analisou-se os objetivos e as principais características operacionais do programa, as mudanças institucionais que estavam em curso e o desempenho em termos de recursos financeiros destinados aos agricultores familiares até aquele momento. Dentre as principais conclusões, destacou-se que o programa possibilitou o acesso ao crédito rural a um grande número de

\footnotetext{
${ }^{1}$ Artigo publicado originalmente como capítulo do livro organizado por Sergio Schneider, Marcelo Kunrath Silva e Paulo Eduardo Moruzzi Marques, "Políticas Públicas e Participação Social no Brasil Rural" (Ed. UFRGS, 2004, p. 21-49). A atual versão passou por ligeiros ajustes para fins de enquadramento às normas da Revista Grifos e sua republicação foi autorizada pela Editora da UFRGS a pedido dos autores.

${ }^{2}$ Professor Titular de Sociologia do Desenvolvimento Rural e Estudos da Alimentação na Universidade Federal do Rio Grande do Sul, Porto Alegre, Rio Grande do Sul, Brasil. Coordenador GEPAD (www.ufrgs.br/agrifood). Bolsista Produtividade em Pesquisa CNPq, PQ1D. E-mail: schneide@ufrgs.br.

3 Professor do Titular da Universidade Federal de Santa Catarina, Programa de Pós-Graduação em Agroecossistemas, bolsista produtividade do CNPq (PQ2) e atual pós-doutorando do Programa de PósGraduação em Sociologia da Universidade Federal do Rio Grande do Sul. E-mail: ademir.cazella@ufsc.br.

${ }^{4}$ Professor Titular dos cursos de Graduação em Economia e de Pós-Graduação em Administração, ambos da UFSC. Coordenador Geral do NECAT-UFSC e Pesquisador do OPPA/CPDA/UFRRJ. E-mail: 1.mattei@ufsc.br.
} 
Revista - Grifos - Unochapecó

Dossiê: PRONAF 25 anos: Histórico, transformações e tendências

agricultores familiares que não estavam inseridos no mercado financeiro, ao mesmo tempo em que o programa ganhou capilaridade nacional, estando presente em todas as regiões do país. Além disso, algumas distorções observadas precisariam ser continuamente corrigidas para que o programa cumprisse na íntegra todas as suas finalidades.

Palavras-chave: Brasil; Política Pública; Agricultura Familiar; Pronaf.

\begin{abstract}
In this article we discuss the importance and the trajectory of the National Program for Strengthening Family Farming (Pronaf), created in 1996. After making a brief discussion over the historical struggles of the organizations of rural workers' in favor of an specific agricultural policy for this social group, in the second section we analyzed the objectives and main operational characteristics of the program, the institutional changes that were underway and the performance in terms of financial resources allocated to family farmers. Among the main conclusions, we highlighted that the program allowed access to rural credit to a large number of family farmers who were not yet inserted in the financial market, and at the same time the program gained national capillarity, being present in all regions of the country. We also observed that some distortions would need to be continually corrected in order the program could fully accomplish all its purposes.
\end{abstract}

Keywords: Brazil; Public Policy; Family Farming; Pronaf.

\title{
RESUMEN
}

En este artículo, se discutió la importancia y la trayectoria del Programa Nacional para Fortalecer la Agricultura Familiar (Pronaf), creado en 1996. Después de una breve discusión sobre el proceso histórico de las luchas de las organizaciones de trabajadores rurales en favor de una política agrícola específicos de este segmento social, se analizaron los objetivos y las principales características operativas del programa, los cambios institucionales que estaban en marcha y el desempeño en términos de recursos financieros asignados a los agricultores familiares hasta ese momento. Entre las principales conclusiones, se destacó que el programa permitió el acceso al crédito rural a un gran número de agricultores familiares que no se insertaron en el mercado financiero, al mismo tiempo que el programa ganó capilaridad nacional, estando presente en todas las regiones del país. Además, algunas distorsiones observadas tendrían que corregirse continuamente para que el programa cumpliera plenamente con todos sus propósitos.

Palabras chave: Brasil; Política pública; Agricultura familiar; Pronaf.

\section{INTRODUÇÃO}

O objetivo deste artigo consiste em elaborar uma síntese da trajetória do PRONAF desde seu surgimento até o presente e apresentar alguns de seus resultados mais 
importantes nas linhas de crédito e infraestrutura e serviços municipais. Não se pretende fazer uma avaliação ou uma abordagem crítica do programa e nem tão pouco dar conta de toda bibliografia recente produzida acerca do seu desempenho e significado. Busca-se apenas descrever o programa com a finalidade de realçar melhor sua trajetória e situá-lo apropriadamente em meio à discussão principal do livro no qual foi originalmente publicado, que se refere aos novos processos de gestão das políticas públicas que têm como alvo os agricultores familiares e o espaço rural brasileiro.

Dentre os acontecimentos mais marcantes que ocorreram na esfera das políticas públicas para o meio rural brasileiro, no período recente, pode-se destacar a criação do Programa Nacional de Fortalecimento da Agricultura Familiar (PRONAF). O surgimento deste programa representa o reconhecimento e a legitimação do Estado, em relação às especificidades de uma nova categoria social - os agricultores familiares - que até então era designada por termos como pequenos produtores, produtores familiares, produtores de baixa renda ou agricultores de subsistência.

De um modo geral, se pode dizer que até o início da década de noventa não existia nenhum tipo de política pública especial, com abrangência nacional, voltada ao atendimento das necessidades desse segmento social da agricultura, o qual era, inclusive, caracterizado de modo meramente instrumental e bastante impreciso no âmbito da burocracia estatal.

É preciso lembrar que, no contexto do início da década de 1990, a agricultura brasileira, e particularmente a da região Meridional do Brasil, estava fortemente afetada pelo processo de abertura comercial e de desregulamentação dos mercados, fatores que a submetiam a uma concorrência intensa com os países do Mercosul. Em vista das sucessivas dificuldades decorrentes da crise da segunda metade dos anos oitenta, particularmente no que se refere à disponibilidade de crédito e da queda da renda, os agricultores familiares da região Sul do Brasil, e em menor medida os agricultores da região Nordeste (sobretudo os produtores de algodão), encontravam-se debilitados diante da nova conjuntura econômica e comercial. 
Revista - Grifos - Unochapecó

Dossiê: PRONAF 25 anos: Histórico, transformações e tendências

Assim, a década de noventa é marcada por alguns fatores que foram decisivos para mudar os rumos do desenvolvimento rural, principalmente na esfera governamental. Por um lado, o movimento sindical dos trabalhadores rurais ligados à Confederação Nacional dos Trabalhadores da Agricultura (CONTAG) e ao Departamento Nacional de Trabalhadores Rurais da Central Única dos Trabalhadores (DNTR/CUT), especialmente dos três estados meridionais do país, passaram a organizar-se e direcionar suas reivindicações e lutas para a chamada "reconversão e reestruturação produtiva" dos agricultores familiares, que seriam afetados pelo processo de abertura comercial da economia, na ocasião influenciado pela criação do Mercosul. Assim, as reivindicações dos trabalhadores rurais, que já haviam começado a ter voz na Constituição de $1988^{5}$, ganharam destaque nas "Jornadas Nacionais de Luta" da primeira metade da década de noventa, que a partir de 1995 passaram a ser denominadas de "Grito da Terra Brasil"6.

Por outro lado, os estudos realizados conjuntamente pela FAO/INCRA ${ }^{7}$ definem com maior precisão conceitual a agricultura familiar e, mais ainda, estabelecem um conjunto de diretrizes que deveriam nortear a formulação de políticas públicas adequadas às especificidades dos diferentes tipos de agricultores familiares. Sabe-se que esses estudos serviram de base para as primeiras formulações do PRONAF.

Entretanto, para melhor compreender este conjunto de inovações, é preciso recuar no tempo e situar o processo de elaboração e consolidação desse Programa. Em larga medida, pode-se afirmar que o PRONAF foi formulado como resposta do Estado às pressões do movimento sindical rural, realizadas desde o final da década de 1980. O programa nasceu com a finalidade de prover crédito agrícola e apoio institucional aos

\footnotetext{
${ }^{5}$ Destacam-se os intensos debates, no âmbito da Comissão de Agricultura do Congresso Nacional, no período entre 1988 a 1993, quando se estabeleceu a Lei Agrícola. Esse período também foi marcado pelas grandes discussões sobre a Lei Agrária, onde as organizações dos trabalhadores rurais transformaram-se em atores importantes e com grande domínio da agenda pública nos dois temas.

${ }^{6}$ Essas "Jornadas" eram organizadas, no início, pela CONTAG, CUT Rural e o Movimento dos Sem Terra (MST), e contavam com a participação de outros movimentos sociais rurais.

7 FAO/INCRA. Diretrizes de política agrária e desenvolvimento sustentável para a pequena produção familiar. Brasília, 1994a, 98p.; e FAO/INCRA. Diretrizes de política agrária e desenvolvimento. Brasília, versão resumida do relatório final do projeto UTF/BRA/036, 1994b, 24p.
} 
pequenos produtores rurais que vinham sendo alijados das políticas públicas até então existentes e encontravam sérias dificuldades de se manter no campo.

Em 1994, em consequiência das reivindicações dos agricultores familiares acima citadas, o governo Itamar Franco criou o Programa de Valorização da Pequena Produção Rural (PROVAP), que operava basicamente com recursos do Banco Nacional de Desenvolvimento (BNDES). O PROVAP seria o embrião da primeira e mais importante política pública criada dois anos mais tarde e destinada aos agricultores familiares. Cabe frisar que, embora o PROVAP tenha tido resultados pífios do ponto de vista dos recursos aportados para os agricultores ${ }^{8}$, sua importância consiste na transição que ali se inicia em direção a uma política pública diferenciada por categorias de produtores rurais. Deve-se lembrar, por exemplo, que até esta época, os pequenos agricultores eram enquadrados como "mini-produtores" pelas normas do Manual de Crédito Rural do Ministério da Agricultura, o que fazia com que tivessem que disputar recursos com os grandes proprietários, que historicamente foram os principais tomadores de crédito para agricultura.

A partir de 1995, já no Governo Fernando Henrique Cardoso, o PROVAP foi totalmente reformulado, tanto em termos de concepção como em sua área de abrangência. Essas modificações deram origem ao PRONAF, em 1996, cuja institucionalização ocorreu através do Decreto Presidencial no 1.946, datado de 28/06/1996. Desse ano em diante, o programa tem se firmado como a principal política pública do Governo Federal para apoiar os agricultores familiares. Deve-se registrar, no entanto, que, no ano de 1996, apenas as ações relativas ao crédito de custeio foram implementadas e que a ampliação do programa para as áreas de investimentos, infra-estrutura e serviços municipais, capacitação e pesquisa, só ocorreu a partir de 1997, quando o PRONAF ganhou maior dimensão e passou a operar de forma integrada em todo território nacional.

\footnotetext{
${ }^{8} \mathrm{Na}$ verdade, o sistema financeiro não está habituado a lidar com esse tipo de cliente, dificultando o acesso dos produtores familiares aos recursos disponibilizados para o crédito rural. 


\section{OBJETIVOS E CARACTERÍSTICAS OPERACIONAIS DO PRONAF}

Segundo o Manual Operacional do PRONAF, o programa visa o fortalecimento da agricultura familiar, mediante apoio técnico e financeiro, para promover o desenvolvimento rural sustentável. Seu objetivo geral consiste em fortalecer a capacidade produtiva da agricultura familiar; contribuir para a geração de emprego e renda nas áreas rurais e melhorar a qualidade de vida dos agricultores familiares. Quatro objetivos específicos complementam os propósitos do programa: a) ajustar as políticas públicas de acordo com a realidade dos agricultores familiares; b) viabilizar a infra-estrutura necessária à melhoria do desempenho produtivo dos agricultores familiares; c) elevar o nível de profissionalização dos agricultores familiares através do acesso aos novos padrões de tecnologia e de gestão social; d) estimular o acesso desses agricultores aos mercados de insumos e produtos.

Do ponto de vista operacional, o PRONAF apresenta, atualmente, quatro grandes linhas de atuação, a saber: a) Crédito de custeio e investimento destinado às atividades produtivas rurais; b) Financiamento de infra-estrutura e serviços a municípios de todas as regiões do país, cuja economia dependa fundamentalmente das unidades agrícolas familiares; c) Capacitação e profissionalização dos agricultores familiares através de cursos e treinamentos aos agricultores, conselheiros municipais e equipes técnicas responsáveis pela implementação de políticas de desenvolvimento rural; d) Financiamento da pesquisa e extensão rural visando a geração e transferência de tecnologias para os agricultores familiares.

Em relação à delimitação do público-alvo, o programa atende especificamente os agricultores familiares, caracterizados a partir dos seguintes critérios:

1) Possuir, pelo menos, $80 \%$ da renda familiar originária da atividade agropecuária;

2) deter ou explorar estabelecimentos com área de até quatro módulos fiscais (ou até 6 módulos quando a atividade do estabelecimento for pecuária);

3) explorar a terra na condição de proprietário, meeiro, parceiro ou arrendatário;

4) utilizar mão-de-obra exclusivamente familiar, podendo, no entanto, manter até dois empregados permanentes; 
5) residir no imóvel ou em aglomerado rural ou urbano próximo;

6) possuir renda bruta familiar anual de até $\mathrm{R} \$ 60.000,00$.

As fontes de financiamento também foram ampliadas. Além do BNDES, o Fundo de Amparo ao Trabalhador (FAT) assumiu o lugar de principal provedor de recursos, representando cerca de 80\% do total desde 1996 até hoje. As outras fontes são os Fundos Constitucionais do Nordeste (FNE) e do Centro-Oeste (FCO), criados pela Constituição de 1988 para favorecer o desenvolvimento das regiões mais pobres; as verbas vindas do Tesouro Nacional, alocadas no Orçamento Geral da União; a Exigibilidade Bancária (percentual de recursos captados pelos bancos comerciais e depositados no Banco Central) e, mais recentemente, os Bancos Cooperativos como o Bansicredi e o Bancoob ${ }^{9}$, que operam com convênios com o Banco do Brasil. Para que os mecanismos de financiamento do PRONAF ganhassem efetividade, coube ao Estado desempenhar um papel crucial na equalização das taxas de juros, das despesas administrativas e, muitas vezes, avalizar as operações para cobrir o risco do sistema bancário. Mesmo assim, depois de mais oito anos de existência, os operadores do PRONAF restringem-se basicamente ao Banco do Brasil e ao Banco do Nordeste, duas instituições públicas.

A modalidade denominada Financiamento da Produção - que comporta os recursos para custeio e investimentos - está voltada ao apoio financeiro dos agricultores familiares, segundo seis categorias de beneficiários ${ }^{10}$ : Essa categorização decorreu da publicação de um estudo realizado no âmbito do convênio FAO/INCRA ${ }^{11}$, em 1999, que sugeriu a segmentação dos agricultores familiares beneficiários do programa em grupos distintos, de acordo com o nível da renda bruta familiar anual. Essa classificação diferenciada dos

\footnotetext{
${ }^{9}$ Em 1995, o Conselho Monetário Nacional autorizou a criação de bancos privados de crédito cooperativo. Nos anos seguintes foram constituídos o Banco do Sistema Sicredi S. A. (Bansicredi), com atuação nos estados do Rio Grande do Sul, Paraná, Mato Grosso e Mato Grosso do Sul, e o Banco Cooperativo do Brasil S. A. (Bancoob) que, no final do ano 2000, atuava em 14 estados brasileiros (BURIGO, 1999; BITTENCOURT, 2001; CAZELLA, 2002).

10 Essas categorias de beneficiários foram definidas pela resolução 2.629, de 10/08/1999, a qual passou a integrar as normas gerais do Manual de Crédito Rural, definidas no capítulo 10.

${ }^{11}$ Um primeiro estudo da FAO/INCRA (1994a) se constituiu em um importante referencial para classificação quantitativa dos estabelecimentos considerados familiares. A partir deste trabalho nasceu a separação entre agricultores patronais e agricultores familiares.
}

\section{DOI: http://dx.doi.org/10.22295/grifos.v30i51.5656 | Edição - Vol. 30, Núm. 51, 2021.}


Revista - Grifos - Unochapecó

Dossiê: PRONAF 25 anos: Histórico, transformações e tendências

agricultores permitiu que as regras de financiamentos fossem mais adequadas à realidade de cada segmento social, sendo que os encargos financeiros e os rebates (descontos) visam auxiliar mais aquelas parcelas com menores faixas de renda e em maiores dificuldades produtivas.

Grupo A: agricultores assentados da reforma agrária que, com a extinção do Programa Especial de Crédito para a Reforma Agrária (PROCERA), passaram a ser atendidos pelo PRONAF. Atualmente, pelas regras do Plano de Safra 2003/04 ${ }^{12}$, esses agricultores podem financiar até $\mathrm{R} \$ 2.500,00$ para custeio da safra e até $\mathrm{R} \$$ 13.500,00 para investimentos. No caso de crédito de custeio, o prazo para pagamento é de dois anos e as taxas de juros são de $2 \%$ ao ano. Já para o crédito de investimento esses números são de 10 anos ( 5 anos de carência) e 1,15\% ao ano, respectivamente. Foi previsto, também, um desconto de $46 \%$ sobre o valor financiado, desde que o pagamento ocorra dentro dos prazos estipulados;

Grupo B: agricultores familiares e remanescentes de quilombos, trabalhadores rurais e indígenas com renda bruta anual atual de até $\mathrm{R} \$ 2.000,00$. Esse grupo inclui as famílias rurais com baixa produção e pouco potencial de aumento da produção no curto prazo localizadas em regiões com concentração de pobreza rural. Os valores dos financiamentos (custeio mais investimento) são limitados em até R \$ 1.000,00 para qualquer atividade geradora de renda, com juros de $1 \%$ ao ano e prazo para pagamento de dois anos, sendo um de carência. Nessa modalidade de crédito, o tomador pode se beneficiar de um desconto de $25 \%$ sobre o valor financiado, quando os prazos de ressarcimento do empréstimo forem respeitados;

Grupo C: agricultores familiares com renda bruta anual atual entre R \$ 2.000,00 a $\mathrm{R} \$ 14.000,00$, que apresentem explorações intermediárias com bom potencial de resposta produtiva. Os limites de financiamento para custeio são de $\mathrm{R} \$ 2.500,00$, com juros de $4 \%$ ao ano, desconto (rebate) de $\mathrm{R} \$ 200,00$ e prazo de pagamento de até dois anos. Já para investimentos, o limite é de $\mathrm{R} \$ 5.000,00$ e o prazo de pagamento de até oito anos, com a mesma taxa de juros. Além do rebate, o agricultor pode se beneficiar de um bônus de $25 \%$ sobre os juros, desde que observados os prazos;

Grupo A/C: agricultores oriundos do processo de reforma agrária e que passam a receber o primeiro crédito de custeio após terem obtido o crédito de investimento inicial que substituiu o antigo programa de apoio aos assentados. Os limites de financiamento de custeio variam de $\mathrm{R} \$ 500,00$ até $\mathrm{R} \$ 2.500,00$, com juros de $2 \%$ ao ano e prazo de pagamento de até dois anos. Esse grupo também é beneficiado por um desconto de $\mathrm{R} \$ 200,00$ sobre o valor emprestado desde que quitado dentro dos prazos estabelecidos;

\footnotetext{
12 Para todos os demais grupos, os valores e prazos também se referem à safra 2003/04.
} 
Revista - Grifos - Unochapecó

Dossiê: PRONAF 25 anos: Histórico, transformações e tendências

Grupo D: agricultores estabilizados economicamente com renda bruta anual entre $\mathrm{R} \$ 14.000,00$ e $\mathrm{R} \$ 40.000,00$, sendo que o limite para custeio é de até $\mathrm{R} \$ 6.000,00$, com juros de $4 \%$ ao ano e prazo de até dois anos. Já para investimento o limite de financiamento é de até $\mathrm{R} \$ 18.000,00$, com prazo de até oito anos e juros iguais ao do custeio, podendo ser reduzido em $25 \%$ o valor referente aos juros para os pagamentos no prazo;

Grupo E (Proger Familiar Rural): agricultores com renda bruta anual entre R \$ $40.000,00$ a $60.000,00$. Os limites de financiamento para custeio são de $\mathrm{R} \$$ $28.000,00$, com juros de 7,25\% ao ano e prazo de pagamento de dois anos. Já para investimento, o limite de financiamento é de $\mathrm{R} \$ 36.000,00$, com juros idênticos ao crédito de custeio e prazo de pagamento de até 8 anos, com 3 são de carência, sem previsão de descontos.

Posteriormente à adoção da segmentação dos beneficiários, ainda em 1999, foram criadas mais três linhas de crédito especiais para os agricultores familiares dos grupos B, C e D. A primeira é o chamado crédito rotativo, também conhecido como Rural Rápido, operado exclusivamente pelo Banco do Brasil. Esse tipo de crédito funciona como um cheque especial em que o agricultor vai utilizando os recursos segundo suas necessidades. Talvez por isto, ele acaba sendo utilizado majoritariamente pelo segmento dos agricultores familiares do grupo D, justamente os mais capitalizados. Segundo Abramovay (2002, p. 38), “em 1997 o crédito rotativo correspondia a 37\% do valor dos financiamentos de custeio do PRONAF e em 2000 ele já chegava a 52\% do total ". A segunda linha de crédito especial é o integrado coletivo, destinado a associações, cooperativas e outras pessoas jurídicas compostas exclusivamente por beneficiários do PRONAF. A terceira linha é o PRONAF-Agregar (Projeto de Agregação de Renda da Agricultura Familiar), destinado a financiar projetos individuais ou coletivos que envolvam infra-estrutura, prestação de serviços, marketing, beneficiamento de produtos, etc. Deve-se mencionar, ainda, que se enquadram nos grupos B, C e D, os pescadores artesanais, os extrativistas, os silvicultores e os aqüicultores, conforme os critérios de renda e dimensão da exploração. Para maiores detalhes consultar Picinatto et al. (2000), Sabbato (2000) e Granzirolli e Cardim (2000). 
Revista - Grifos - Unochapecó

Dossiê: PRONAF 25 anos: Histórico, transformações e tendências

\section{AS PRINCIPAIS MUDANÇAS OCORRIDAS NO PRONAF}

A partir de 1999, com o início do segundo Governo FHC, o PRONAF passou por novas reformulações. Institucionalmente, o programa deixou de fazer parte do Ministério da Agricultura, onde estava vinculado à então Secretaria de Desenvolvimento Rural, passando a ser incorporado pelo recém-criado Ministério do Desenvolvimento Agrário (MDA). O MDA substituiu o Ministério Extraordinário de Assuntos Fundiários, criado em 1995, tendo antes a condição de Secretaria de Estado ${ }^{13}$. O MDA passou a abrigar o Instituto Nacional de Colonização e Reforma Agrária (INCRA), instituição encarregada da política fundiária e de assentamentos da reforma agrária e, no lugar da Secretaria de Desenvolvimento Rural, foi criada a Secretaria da Agricultura Familiar (SAF), que passou a ser o guarda-chuva institucional das diversas linhas de ação do PRONAF e demais programas ligados à agricultura familiar brasileira. Nessa nova estrutura organizacional, o tema da agricultura familiar ganhou mais espaço, tanto na esfera pública federal como na sua visibilidade junto à sociedade civil.

Deve-se registrar que uma nova reformulação institucional foi realizada na SAF em 2003, no início do Governo Lula, com implicações sobre o PRONAF. No âmbito do MDA foi criada a Secretaria do Desenvolvimento Territorial (SDT), a qual passou a definir e gerenciar a modalidade do PRONAF infra-estrutura e serviços municipais. Maiores detalhes sobre as implicações dessa mudança serão abordados na seção seguinte.

Um terceiro grupo de reformulações concentra-se na esfera financeira, provocando uma série de mudanças no programa, principalmente no tocante às taxas de juros e às

\footnotetext{
${ }^{13} \mathrm{O}$ Ministério Extraordinário de Assuntos Fundiários surge em um contexto de ascendência das lutas sociais no campo e, particularmente, de acirramento da luta pela terra no Brasil. De um lado, a pressão dos pequenos agricultores ligados à CONTAG reivindicando políticas específicas de compensação pela chamada "âncora verde" que a agricultura proporcionara à estabilização de preços no Plano Real, durante o primeiro governo FHC. De outro, o MST amplia sua base social e estende sua esfera de atuação para o estado de São Paulo (Pontal do Paranapanema), ganhando com isto uma projeção nacional. Mas não se pode negar que os fatos políticos decisivos deste período são os massacres de agricultores sem terra em Corumbiara - Rondônia (agosto de 1995) e Eldorado de Carajás, no sul do Pará (abril de 1996), ambos seguidos de uma "marcha à Brasília", realizada em abril de 1997, que culminou com um comício que se estima tenha reunido em torno de 100 mil pessoas. Dada a repercussão nacional e internacional destes acontecimentos o governo federal assume
} 
Revista - Grifos - Unochapecó

Dossiê: PRONAF 25 anos: Histórico, transformações e tendências

formas de pagamento dos empréstimos bancários. No que diz respeito aos juros, a resolução 2.766 de 2000, do Banco Central atendeu a uma antiga reivindicação dos agricultores familiares, ou seja, a definição de uma taxa fixa. Com isso, verifica-se que houve uma redução progressiva dos encargos financeiros, chegando-se ao estágio atual com taxas de juros que variam entre 1\% (Grupo B) e 7,25\% (Grupo E). Além disso, os prazos e carências foram sendo dilatados, conjuntamente com a elevação dos valores dos descontos sobre os valores referentes aos juros. Em grande medida, essas modificações visaram atender a um número maior de beneficiários e expandir a esfera de interferência da agricultura familiar nas tomadas de decisões acerca dos rumos da produção agropecuária do país.

As diversas reformulações legais que afetaram todas as diferentes modalidades do programa, sobretudo nos últimos anos, podem ser resumidas da forma como segue:

a) Criação, através da resolução 2.436 do Banco Central, de 1997, da linha especial de crédito de custeio conhecida como "Pronafinho" (Grupo C), destinando créditos (na época) de até $\mathrm{R} \$ 1.500,00$, com o objetivo de direcionar parte dos recursos de custeio aos agricultores mais necessitados;

b) Criação pelo Banco do Brasil, em 1997, da modalidade "BB Rural Rápido", com o objetivo de agilizar a liberação de financiamentos para aqueles agricultores que possuem cadastro junto ao Banco do Brasil;

c) Criação, em 1996, do PRONAF Infra-estrutura e serviços municipais, com o objetivo de melhorar as condições de produção e de infra-estrutura nos municípios rurais, onde a agricultura familiar representa um papel estratégico na economia local;

d) Criação do PRONAF Agroindústria, no ano de 1998, com o objetivo de financiar projetos de grupos de agricultores;

e) Criação, em 1998, da linha de crédito de investimento conhecida como PRONAF Agregar, com o objetivo de agregar renda às atividades agropecuárias;

f) Fusão, através da resolução 2.766, de 2000, das linhas de crédito de investimento Agregar e Agroindústria em uma única, com o nome de Crédito de Investimento para Agregação de Renda à Atividade Rural. Essa modalidade, ainda conhecida como PRONAF Agregar tem como objetivo liberar recursos para o beneficiamento, processamento e comercialização da produção agropecuária, sendo destinada aos agricultores dos grupos B, C e D;

uma nova postura em relação ao problema agrário e cria o Ministério Extraordinário de Política Fundiária, em 1995 (CARVALHO FILHO, 2001, p. 203). 
g) Extensão do crédito de custeio e das demais modalidades do programa, a partir de 2000, aos assentados da reforma agrária (grupo A/C), que já foram contemplados com recursos de investimentos para estruturação das unidades;

h) Criação, pela resolução 3.001 do Banco Central, de 2002, da linha de crédito de investimentos para silvicultura e sistemas agroflorestais (Pronaf Florestal), destinada aos agricultores dos grupos B, C e D, com o objetivo de apoiar os investimentos em florestas;

i) Criação, na safra 2003/04, de novas modalidades: PRONAF Alimentos, com o objetivo de estimular a produção de cinco alimentos básicos (arroz, feijão, milho, mandioca e trigo); PRONAF Pesca, com o objetivo de apoiar os pescadores artesanais; PRONAF Agroecologia, com o objetivo de apoiar a produção agropecuária que não utiliza produtos químicos e também os agricultores que se encontram em transição para este tipo de produção; PRONAF Turismo Rural, com o objetivo de apoiar a implantação de atividades turísticas nas propriedades rurais; PRONAF Mulher; PRONAF Jovem Rural; PRONAF Semi-Árido e PRONAF Máquinas e equipamentos.

Outra reestruturação do programa foi com relação às declarações de aptidão fornecidas aos agricultores. No caso do crédito para custeio e investimento para os beneficiários da reforma agrária, enquadrados no Grupo A, elas passaram a ser fornecidas pelo INCRA. Para os demais grupos de agricultores, o Ministério do Desenvolvimento Agrário habilitou os Sindicatos dos Trabalhadores Rurais, os serviços públicos de extensão rural e os Sindicatos Rurais a emitir essas declarações.

Em face destas mudanças, o PRONAF passou a ter uma importância decisiva para a agricultura familiar brasileira, a partir da segunda metade da década de 1990. Malgrado possíveis críticas em relação à execução orçamentária destinada ao programa, os dados mostram que o volume de recursos destinados e aplicados na agricultura familiar vem aumentando sucessivamente desde a safra 1996/97, quando o PRONAF passou a ter abrangência nacional. Além disso, parece indiscutível que essa política pública está ainda em construção e que continuará exigindo adaptações contínuas devido à diversidade social dos agricultores familiares e às diferenças regionais. 


\section{ALGUNS INDICADORES DE DESEMPENHO DAS PRINCIPAIS LINHAS DE AÇÃO DO PRONAF}

Em relatório de pesquisa sobre o PRONAF, Abramovay (2002, p.2) ressaltou que, ao longo dos seus seis anos de existência, o programa forjou três importantes inovações, a saber: o reconhecimento dos agricultores familiares como protagonistas das políticas públicas; a criação de um processo de negociação entre os agricultores e suas organizações e o governo; e o estabelecimento de um enfoque territorial para as políticas públicas, ressaltando-se, neste caso, o papel dos Conselhos Municipais de Desenvolvimento Rural (CMDR) criados por demanda do PRONAF Infra-estrutura e serviços municipais. Nesta seção pretendemos explorar essas questões. Para tanto, serão abordados os principais aspectos relativos a duas das grandes linhas de intervenção do programa, já citadas anteriormente: crédito de custeio e investimento e o PRONAF Infra-estrutura e serviços municipais.

\section{Crédito de custeio e investimento}

A sistemática de concessão de crédito vem sofrendo contínuas alterações desde o início dessa política, sobretudo no que diz respeito aos valores dos financiamentos para custeio e para investimento, bem como no que se refere às taxas de juros que incidem sobre os recursos alocados no programa. Desse modo, a discussão que apresentamos a seguir contemplará o primeiro período do programa (1995-1998), com ênfase para a distribuição dos recursos por categorias de agricultores iniciada em 1999, conforme descrito na seção anterior.

É importante destacar, em primeiro lugar, que a modalidade de crédito para custeio representa um valor expressivo do volume total de recursos efetivamente aplicados nos últimos anos no quadro do PRONAF, enquanto que a modalidade de crédito para investimentos começou a operar de forma mais significativa somente após o ano de 1997. Isso significa que o programa apresentou, no primeiro período, um forte direcionamento do 
crédito para o financiamento das safras anuais e uma intervenção bem menor sobre os problemas relacionados à infra-estrutura dos sistemas de produção.

A evolução do programa, em termos do número de contratos efetivados e do volume de recursos aplicado, é mostrada pela Tabela 1, que segue. Inicialmente, observa-se que no primeiro ano do programa (1995) houve um pequeno número de financiamentos, com baixo uso de recursos, sendo que o total disponibilizado foi destinado para o crédito de custeio da safra agrícola. Em grande medida, a explicação para o comportamento pouco expressivo do PRONAF naquele ano diz respeito às dificuldades enfrentadas pelos agricultores diante das condições de financiamento vigentes.

A partir de 1996, nota-se um forte incremento do total de recursos aplicados no programa e da própria procura pelo crédito rural, a qual se expressa através da elevação do número de contratos. Essa alteração deve-se a um somatório de fatores que atuaram positivamente. Por um lado, o Conselho Monetário Nacional (CMN) adotou uma série de medidas para estimular os agentes financeiros a operar o PRONAF e, por outro, reduziu-se bastante os encargos financeiros que incidiam sobre o crédito de custeio (os juros praticados na safra de 1995 foram de $16 \%$ ao ano, enquanto que na safra seguinte caíram para $12 \%$ ao ano). Deve-se destacar que essa mudança foi efetivada devido à forte pressão exercida pelas organizações dos trabalhadores rurais que exigiram melhores condições de financiamento.

Tabela 1 - Número de contratos e volume de recursos do primeiro período do PRONAF

\begin{tabular}{c|c|c|c}
\hline Ano & $\mathbf{N}^{\mathbf{o}}$ de contratos & Recursos $(\mathbf{R} \mathbf{\$ 1 0 0 0})$ & Valor Médio $(\mathbf{R} \mathbf{\$})$ \\
\hline 1995 & 32.000 & $93.000,00$ & $2.906,25$ \\
1996 & 332.828 & $649.795,00$ & $1.952,30$ \\
1997 & 496.550 & $1.637 .440,00$ & $3.297,60$ \\
1998 & 709.906 & $1.814 .972,00$ & $2.556,60$ \\
\hline TOTAL & $\mathbf{1 . 5 7 1 . 2 8 4}$ & $\mathbf{4 . 1 9 5 . 2 0 7 , 0 0}$ & $\mathbf{2 . 6 6 9 , 9 2}$ \\
\hline
\end{tabular}

Fonte: MDA/SAF

A tabela acima apresenta um outro indicador importante que precisa ser considerado, uma vez que desde 1995 o Banco Central não registra mais, de forma estratificada, o destino do crédito rural por setor social. Com isso, o valor médio dos contratos assume grande relevância na discussão dos beneficiários do programa. Nesse 
período, foi estabelecido como limite máximo de financiamento o valor de $\mathrm{R} \$ 5.000,00$. Vemos que os contratos efetuados se situaram bem abaixo desse teto, o que significa que um número razoável de agricultores se beneficiou dessa política pública, a qual possibilitou um novo tipo de relacionamento entre os agentes financeiros e os agricultores, considerando-se o fato de que operações bancárias abaixo do valor máximo fixado pelo programa são pouco atraentes para o sistema financeiro.

Por fim, convém destacar que esses valores médios dos contratos variam muito entre as regiões e mais fortemente entre as unidades da federação. De alguma forma, essas variações refletem os diferentes sistemas de produção e os distintos tipos de produtos incentivados pelo PRONAF em cada um dos estados brasileiros.

A Tabela 2, a seguir, apresenta a distribuição espacial dos contratos e dos recursos por regiões do país. Tomando-se como base o ano de 1996, percebe-se que nesse período houve uma forte concentração, tanto dos contratos (78\% do total) como dos recursos (65\%), na região Sul. As demais regiões tiveram o seguinte desempenho: Norte com $3 \%$ dos contratos e 10\% dos recursos; Nordeste com 13\% dos contratos e dos recursos; Sudeste com $5 \%$ dos contratos e $10 \%$ dos recursos; e Centro-Oeste com $1 \%$ dos contratos e $2 \%$ dos recursos.

Isso significa que no primeiro período ocorreu um forte desequilíbrio espacial do programa. Dentre as explicações que podem justificar essas desigualdades na aplicação dos recursos do PRONAF, destacam-se os seguintes aspectos:

a) o peso econômico e as pressões políticas das agroindustriais da região Sul sobre os órgãos responsáveis pela alocação dos recursos financeiros. No ano de 1996, por exemplo, $32 \%$ do total dos contratos de crédito para custeio foram para a cultura do fumo, $14 \%$ para a cultura do milho e $8 \%$ para a cultura da soja, indicando um alto grau de concentração dos recursos do PRONAF em produtos típicos das cadeias agroindustriais mais competitivas no mercado internacional;

b) um nível maior de organização dos agricultores familiares e uma certa tradição de luta pelo crédito rural mais fortemente incorporada à pauta de reivindicação dos agricultores familiares da região Sul. 
Tabela 2 - Distribuição dos contratos e dos recursos do PRONAF por regiões do país

\begin{tabular}{|c|c|c|c|}
\hline REGIÃO & 1996 & 1997 & 1998 \\
\hline $\begin{array}{l}\text { NORTE } \\
\text { Contratos } \\
\text { Valor (R\$ 1000) } \\
\text { Valor Médio (R\$) }\end{array}$ & $\begin{array}{c}8.872 \\
65.974,81 \\
7.436,20 \\
\end{array}$ & $\begin{array}{c}6.337 \\
23.722,15 \\
3.743,41 \\
\end{array}$ & $\begin{array}{c}11.489 \\
27.385,00 \\
2.383,58\end{array}$ \\
\hline $\begin{array}{l}\text { NORDESTE } \\
\text { Contratos } \\
\text { Valor (R\$ 1000) } \\
\text { Valor Médio (R\$) }\end{array}$ & $\begin{array}{c}44.536 \\
84.443,80 \\
1.896,10 \\
\end{array}$ & $\begin{array}{c}81.871 \\
166.025,57 \\
2.027,89\end{array}$ & $\begin{array}{c}174.642 \\
677.070,00 \\
3.876,90 \\
\end{array}$ \\
\hline $\begin{array}{l}\text { SUDESTE } \\
\text { Contratos } \\
\text { Valor (R\$ 1000) } \\
\text { Valor Médio (R\$) }\end{array}$ & $\begin{array}{c}16.364 \\
67.842,56 \\
4.145,80\end{array}$ & $\begin{array}{c}61.338 \\
290.386,63 \\
4.734,20\end{array}$ & $\begin{array}{c}80.693 \\
255.204,00 \\
3.162,65\end{array}$ \\
\hline $\begin{array}{l}\text { SUL } \\
\text { Contratos } \\
\text { Valor (R\$ 1000) } \\
\text { Valor Médio (R\$) }\end{array}$ & $\begin{array}{c}259.134 \\
420.282,46 \\
1.621,87\end{array}$ & $\begin{array}{c}332.307 \\
1.048 .839,22 \\
3.156,24\end{array}$ & $\begin{array}{c}429.707 \\
787.778,00 \\
1.833,30\end{array}$ \\
\hline $\begin{array}{l}\text { C.OESTE } \\
\text { Contratos } \\
\text { Valor (R\$ 1000) } \\
\text { Valor Médio (R\$) }\end{array}$ & $\begin{array}{c}3.922 \\
11.252,28 \\
2.868,90\end{array}$ & $\begin{array}{c}14.697 \\
108.466,59 \\
7.380,15\end{array}$ & $\begin{array}{c}13.375 \\
67.535,00 \\
5.037,38\end{array}$ \\
\hline
\end{tabular}

Nota: as informações referentes ao ano de 1995 não estão disponíveis regionalmente.

Em termos do valor médio dos contratos, verifica-se que em todas as regiões esse valor não atingiu o teto máximo do programa que era de $\mathrm{R} \$ 5.000,00$. Entretanto, a dinâmica regional revela dois casos extremos: por um lado, a região Sul apresenta os menores valores e, por outro, a região Centro-Oeste detém os maiores valores médios dos contratos. De alguma forma, esses resultados indicam que tanto na região Sul como na região Nordeste, que possuem um grande número de contratos, a escala produtiva dos agricultores familiares é menor, comparativamente aos agricultores das regiões CentroOeste e Norte, que possuem contratos com valores maiores.

O segundo período que estamos considerando compreende as safras agrícolas pós1999, ano em que o programa foi bastante reformulado e, como dissemos anteriormente, os recursos passaram a ser estratificados por categorias de beneficiários, de acordo com as regras de enquadramentos vigentes desde então.

A Tabela 3, a seguir, apresenta o montante de crédito rural para custeio e investimento para o período pós-1999. Inicialmente observa-se que os recursos para custeio 
Revista - Grifos - Unochapecó

Dossiê: PRONAF 25 anos: Histórico, transformações e tendências

das safras agrícolas correspondem a mais de $60 \%$ do total de recursos previstos em cada safra, significando que o programa tem uma maior influência no financiamento das safras agrícolas Além disso, deve-se registrar que o montante total dos recursos para custeio no período considerado se manteve praticamente constante. Em termos do número de contratos nota-se, inclusive, uma redução na última safra, o que significa que os valores médios passaram de R\$1.849,56, em 1999, para R\$2.115,69, em 2003.

Tabela 3 - Número de contratos e montante de crédito do PRONAF por safra agrícola, segundo as modalidades de crédito rural. Brasil, 1999-2003

\begin{tabular}{|c|c|c|c|}
\hline Safra Agrícola & Modalidade do Crédito & $\mathbf{N}^{0}$ de Contratos & Montante (R\$ 1,00) \\
\hline \multirow[t]{2}{*}{$1999-2000$} & Custeio & 735.454 & $1.360 .267 .678,75$ \\
\hline & Investimento & 192.155 & $791.817 .069,70$ \\
\hline Sub-total & - & 927.609 & $2.152 .084 .748,45$ \\
\hline \multirow[t]{2}{*}{$2000-2001$} & Custeio & 745.011 & $1.451 .547 .952,70$ \\
\hline & Investimento & 148.101 & $716.938 .275,81$ \\
\hline Sub-total & - & 893.112 & $2.168 .486 .228,51$ \\
\hline \multirow[t]{2}{*}{$2001-2002$} & Custeio & 688.577 & $1.332 .122 .515,38$ \\
\hline & Investimento & 244.135 & $856.673 .225,61$ \\
\hline Sub-total & - & 932.712 & 2.188.795.740,99 \\
\hline \multirow[t]{2}{*}{$2002-2003$} & Custeio & 654.160 & $1.384 .005 .981,89$ \\
\hline & Investimento & 247.177 & $976.487 .240,91$ \\
\hline Sub-total & - & 901.337 & $2.360 .493 .222,80$ \\
\hline Total & - & 3.654 .770 & $8.859 .859 .940,75$ \\
\hline
\end{tabular}

Em termos do enquadramento dos beneficiários, percebe-se um comportamento bem distinto para cada uma das modalidades de crédito da tabela acima. Na safra de 19992000, dos 735.454 contratos de custeio, 303.127 foram para o grupo C (41\%) e 337.626 foram para o grupo D $(46 \%)$. O restante dos contratos foi para a categoria "sem enquadramento", que são os recursos da exigibilidade bancária. Já na safra de 2002-2003, dos 654.160 contratos de custeio, 389.580 foram para o grupo C (60\%) e 243.727 foram para o grupo D (37\%). Ainda nesta safra, 10.550 contratos (1,5\% do total) foram destinados ao grupo $\mathrm{A} / \mathrm{C}$, que são os beneficiários egressos dos assentamentos de reforma agrária. Essas informações revelam que os recursos do crédito de custeio, que são a maioria absoluta, apresentam uma tendência a beneficiar de forma crescente um segmento da agricultura familiar brasileira que, até bem pouco tempo, encontrava-se praticamente 
excluído da política de financiamento agrícola. Trata-se dos agricultores familiares enquadrados no Grupo C, que apresentam renda bruta anual atual entre $\mathrm{R} \$ 2.000,00$ a $\mathrm{R} \$$ $14.000,00$.

Quanto ao crédito para investimentos nota-se um comportamento um pouco distinto no período considerado. Assim, dos 192.155 contratos executados na safra 1999-2000, 116.796 foram para o grupo A (61\%); 21.525 para o grupo C (11\%); 53.790 para o grupo D (28\%). Os demais contratos estão na categoria "sem enquadramento". Em termos da participação de cada grupo no montante dos recursos os percentuais foram, respectivamente, de $54 \%, 8 \%$ e $37 \%$.

Já na safra 2002-2003, dos 247.177 contratos de investimento, 46.797 foram para o grupo A (19\%); 139.786 para o grupo B (56\%); 31.721 o grupo C (13\%); 28.864 contratos para o grupo D (12\%). Em termos da participação de cada grupo no montante dos recursos os percentuais foram, respectivamente, de $47 \%, 7 \%, 19 \%$ e $26 \%$. Essas informações retratam as disparidades socioeconômicas da agricultura familiar brasileira, uma vez que os agricultores do Grupo B, de menor capacidade produtiva, representam 56\% dos contratos, mas detém apenas $7 \%$ do total dos recursos da modalidade, ao passo que os do Grupo D, segmento da agricultura familiar inserido nos mercados, com apenas $12 \%$ dos contratos, foram beneficiados com $26 \%$ dos recursos. Dessa forma, chama a atenção a expressiva participação dos agricultores familiares já consolidados no montante de recursos financeiros do PRONAF.

Embora o financiamento à produção nas modalidades de crédito para custeio e investimento seja o mais destacado e reconhecido entre as ações do PRONAF, a linha de financiamentos para Infra-estrutura e serviços municipais representa uma grande inovação. Na realidade, se é possível afirmar que o PRONAF se caracteriza como um programa de desenvolvimento rural, essa assertiva certamente assume contornos mais nítidos na linha de Infra-estrutura e serviços, conforme discutimos no item seguinte. 
Revista - Grifos - Unochapecó

Dossiê: PRONAF 25 anos: Histórico, transformações e tendências

\section{Financiamento de infraestrutura e serviços municipais}

Segundo Lima Neto (2000), os objetivos do PRONAF Infra-estrutura e serviços municipais buscam estimular a implantação, ampliação, modernização, racionalização e relocalização de infra-estrutura e serviços públicos municipais necessários ao fortalecimento da agricultura familiar, tais como: recuperação de estradas vicinais, linha tronco de energia elétrica, construção de armazéns comunitários e obras hídricas de uso coletivo. Essa linha do PRONAF visa contribuir para a eliminar gargalos que estejam retardando ou impedindo o desenvolvimento de zonas onde predomina a agricultura familiar, promovendo melhorias nos canais de escoamento da produção, no acesso a novas tecnologias e na competitividade no mercado.

Essa linha do PRONAF foi criada em 1996, pelo Decreto Presidencial no 1946 de 28 de junho. Nesse ano, ela foi implementada em 389 municípios do Brasil, contando basicamente com a ajuda das organizações de agricultores familiares, Conselhos e Secretarias executivas estaduais do PRONAF. O principal problema dessa primeira fase é que não tinham sido definidos os critérios de seleção dos municípios a serem beneficiados e tão pouco uma metodologia de trabalho.

Para resolver essa situação, foi constituído o Conselho Nacional do PRONAF e, a partir dele, estabelecidas as normas gerais para a seleção dos municípios beneficiários do programa $^{14}$. Estas normas para seleção constam da Resolução nº 4, de 10 de julho de 1997 , do Conselho Nacional do PRONAF, podendo-se destacar os seguintes aspectos:

1. a relação entre o número de estabelecimentos agropecuários com área até 200 ha e o número total de estabelecimentos do município tem que ser maior que a relação entre o número de estabelecimentos com área até 200 ha e o total de estabelecimentos do estado;

2. a relação entre a população rural e a população total do município deve ser maior que a mesma relação no âmbito do estado;

${ }^{14}$ O Conselho Nacional do PRONAF foi incorporado, mais tarde, ao Conselho Nacional de Desenvolvimento Rural Sustentável (CNDRS), criado pelo Decreto 3.200, de 06 de outubro de 1999. A partir de então todas as ações do PRONAF passaram a estar subordinadas ao CNDRS. 
Revista - Grifos - Unochapecó

Dossiê: PRONAF 25 anos: Histórico, transformações e tendências

3. o valor da produção agrícola por pessoa ocupada no município deve ser menor que a mesma relação no plano estadual;

4. caso o número de municípios selecionados a partir desses três critérios fosse inferior ao número previsto para o estado, o Conselho Estadual do PRONAF tem a prerrogativa de selecionar os municípios restantes dentre os que atendiam a apenas dois dos três critérios, dando prioridade aos municípios contemplados no programa Comunidade Solidária e aos que tivessem maior número de famílias assentadas e/ou de pescadores artesanais ${ }^{15}$.

Desde o princípio, ficou definido que os municípios escolhidos teriam acesso ao valor médio anual de $\mathrm{R} \$ 150.000,00$ previsto para um período de quatro anos. A partir do estabelecimento desses critérios, o número de municípios beneficiados aumentou rapidamente, conforme indicam, a seguir, os dados da Tabela 4. A grande inclusão de municípios ocorreu entre os anos de 1997 e 1999, uma vez que em 1999 o programa foi ampliado para mais de mil municípios. Já a partir do ano de 2000 ocorreu um ligeiro recuo, o que de alguma forma pode estar revelando as dificuldades dessa modalidade de política para atender as demandas do universo dos municípios onde a agricultura familiar representa a base do setor produtivo local, estimado atualmente em mais de quatro mil municípios.

Tabela 4 - Número de municípios beneficiados pelo PRONAF Infra-Estrutura e Serviços -

\begin{tabular}{l|c|c|c|c|c}
\hline \multicolumn{7}{|c}{$1997-2001 *$} \\
\hline Região & $\mathbf{1 9 9 7}$ & $\mathbf{1 9 9 8}$ & $\mathbf{1 9 9 9}$ & $\mathbf{2 0 0 0}$ & $\mathbf{2 0 0 1}$ \\
\hline Norte & 48 & 75 & 120 & 109 & 161 \\
Nordeste & 138 & 258 & 392 & 331 & 628 \\
Sudeste & 96 & 152 & 227 & 212 & 235 \\
Sul & 135 & 153 & 170 & 170 & 147 \\
Centro-Oeste & 44 & 74 & 97 & 94 & 82 \\
\hline Total & $\mathbf{4 6 1}$ & $\mathbf{7 1 2}$ & $\mathbf{1 0 0 6}$ & $\mathbf{9 1 6}$ & $\mathbf{1 2 5 3}$ \\
\hline
\end{tabular}

Fonte: SAF, CEF e OGU.

*Após 2001 houve um aumento do número de municípios beneficiados pelo Programa, mas não se dispõe de dados agregados para as diferentes regiões nas fontes citadas.

Interessante observar a distribuição dos recursos, pois as regiões mais pobres, como o Nordeste, foram priorizadas, numa tentativa de reduzir as desigualdades regionais. A análise dos Planos de Trabalhos dos municípios dessa região revela que os mesmos contêm 
Revista - Grifos - Unochapecó

Dossiê: PRONAF 25 anos: Histórico, transformações e tendências

os maiores valores médios do país, especialmente os planos dos estados da Bahia e do Piauí. Dentre as razões que explicam esse comportamento encontra-se o financiamento de obras mais dispendiosas, como são os casos ligados ao abastecimento de água, considerado um problema crucial em muitos estados da região Nordeste.

A Tabela 5, a seguir, mostra como está a distribuição dos recursos entre as grandes regiões do país. Inicialmente, percebe-se que a participação percentual de cada região manteve-se praticamente inalterada ao longo de todo o período considerado, com a região Nordeste detendo aproximadamente $40 \%$ dos recursos liberados a cada ano pelo programa, exceto no ano de 2001, quando essa região concentrou $66 \%$ do total dos recursos liberados. O mesmo fato também foi verificado para a região Norte que aumentou seu percentual de participação na distribuição dos recursos de 12\%, em 2000, para 16\%, em 2001. Com isso, as demais regiões sofreram uma forte retração na participação percentual dos recursos, sendo que no Sul o percentual se reduziu de 17\%, em 2000, para 5\%, em 2001; no Sudeste a participação passou de $23 \%$ para $11 \%$; e no Centro-Oeste de $10 \%$ para $3 \%$, no mesmo período.

Tabela 5 - Evolução da distribuição dos recursos por Grandes Regiões do País (R\$1000)

\begin{tabular}{l|r|c|r|r|r|r}
\hline Região & \multicolumn{1}{|c|}{$\mathbf{1 9 9 7}$} & $\mathbf{1 9 9 8}$ & $\mathbf{1 9 9 9}$ & \multicolumn{1}{c|}{$\mathbf{2 0 0 0}$} & \multicolumn{1}{|c|}{$\mathbf{2 0 0 1}$} & \multicolumn{1}{c}{ TOTAL } \\
\hline Norte & $5.882,00$ & $10.405,00$ & $18.279,00$ & $18.739,00$ & $26.791,00$ & $80.096,00$ \\
Nordeste & $24.197,00$ & $32.189,00$ & $61.564,00$ & $58.885,00$ & $113.100,00$ & $289.935,00$ \\
Sudeste & $12.728,00$ & $21.038,00$ & $32.436,00$ & $34.302,00$ & $18.118,00$ & $118.622,00$ \\
Sul & $14.798,00$ & $12.015,00$ & $23.861,00$ & $25.448,00$ & $7.818,00$ & $83.940,00$ \\
C.Oeste & $5.954,00$ & $10.274,00$ & $14.200,00$ & $14.488,00$ & $4.483,00$ & $49.399,00$ \\
\hline Total & $\mathbf{6 3 . 5 5 9 , 0 0}$ & $\mathbf{8 5 . 9 2 1 , 0 0}$ & $\mathbf{1 5 0 . 3 4 0 , 0 0}$ & $\mathbf{1 5 1 . 8 6 2 , 0 0}$ & $\mathbf{1 7 0 . 3 1 0 , 0 0}$ & $\mathbf{6 2 1 . 9 9 2 , 0 0}$ \\
\hline \multicolumn{7}{c}{ Fonte: MDA/SAF }
\end{tabular}

A partir 1999, com a criação do Conselho Nacional de Desenvolvimento Rural Sustentável, os critérios de seleção dos municípios sofreram uma nova reformulação. A primeira delas ocorreu através da Resolução $n^{\circ} 15$, de maio de 2001 , que, dentre outras coisas, precisou as incumbências do Conselho Estadual do PRONAF, como a elaboração da

\footnotetext{
15 Para uma discussão dos critérios de seleção dos municípios, ver Veiga e Abramovay (1997). Análise (diagnóstico) da inserção do PRONAF na política agrícola: $1^{\circ}$ relatório (de andamento). São Paulo, Convênio IPEA/FIPE $\mathrm{n}^{\circ}$ 07/97, 30p.
} 
Revista - Grifos - Unochapecó

Dossiê: PRONAF 25 anos: Histórico, transformações e tendências

lista final dos municípios contemplados e a previsão de contrapartidas dos municípios beneficiados com recursos do PRONAF Infra-estrutura ${ }^{16}$.

Além disso, essa Resolução acrescentou critérios adicionais visando privilegiar os municípios mais pobres e mais rurais, utilizando-se de indicadores como o Índice de Desenvolvimento Humano (IDH) ${ }^{17}$. Mas a mudança mais relevante, que consta no Artigo $9^{\circ}$ da referida Resolução, passou a ser a exigência de se instituir os Conselhos Municipais de Desenvolvimento Rural (CMDR) e a elaboração de Planos Municipais de Desenvolvimento Rural (PMDR), assim como tornar disponível uma infra-estrutura mínima para garantir o funcionamento desses Conselhos ${ }^{18}$, tais como a alocação de espaço físico identificado com os dizeres "Sala do Agricultor Familiar - PRONAF"; um servidor para atendimento público; um técnico para acompanhar e supervisionar os beneficiários e a criação de um programa municipal de compras para a agricultura familiar.

A ênfase dada à constituição de CMDR deve-se ao fato que o PRONAF Infraestrutura, diferentemente da linha de crédito rural, tem como pressuposto básico o envolvimento das comunidades rurais e dos agricultores familiares na concepção, gestão e fiscalização das políticas públicas. Essa prerrogativa, em grande parte, advém da necessidade crescente do Estado estimular formas de gestão descentralizadas que promovam, ao mesmo tempo, maior eficiência no uso dos recursos e ampliação dos mecanismos de acesso da população, levando a uma maior democratização.

Nesse sentido, para que os municípios pudessem acessar os recursos do Programa, criou-se uma metodologia de elaboração de projetos que previa não apenas a participação de múltiplas instituições locais da sociedade civil (sindicatos, ONGs, associações de

\footnotetext{
${ }^{16}$ A contrapartida dos governos municipais prevista na época seguia a seguinte regra: municípios com até 25.000 habitantes e que faziam parte do Programa Comunidade Solidária ou Comunidade Ativa, a contrapartida mínima era de 1\%; municípios com até 25.000 habitantes e que não faziam parte desses Programas, a contrapartida mínima subia para 4\%; municípios com população acima de 25.000 habitantes e que faziam parte de apenas um dos Programas, a contrapartida mínima era de 5\%; por fim, os municípios cuja população ultrapassava a casa dos 25.000 habitantes e que não faziam parte dos Programas, a contrapartida mínima atingia $20 \%$.

17 A metodologia do Programa das Nações Unidas para o Desenvolvimento (PNUD) para calcular o IDH considera três variáveis principais: a esperança de vida, o nível educacional e o PIB real per capita.

${ }^{18}$ A criação de CMDR havia sido prevista no Decreto $n^{\circ} 3.508$, de 14 de julho de 2000.
} 
produtores, etc), mas a constituição formal de um espaço público de negociação cuja atribuição maior seria coordenar e planejar as ações e políticas públicas destinadas aos agricultores. Através dos CMDR, esperava-se constituir um espaço institucional cujas incumbências não se restringiam a uma arena de atuação política das entidades da sociedade civil, mas também a de ser uma estrutura com poderes para legitimar a condução das iniciativas locais, administrar os recursos existentes e zelar pela sua correta aplicação.

A importância dos CMDR enquanto célula gestora de base do Programa foi reforçada pela Resolução $n^{\circ} 28$, de 28 de fevereiro de 2002. Na ocasião se estabeleceram as premissas para o reconhecimento e a valorização desses Conselhos, indicando a centralidade que essas instâncias de planejamento, coordenação e fiscalização passariam a assumir para o programa.

Percebe-se, portanto, que os CMDR assumiram um papel de destaque na condução do PRONAF Infra-estrutura no âmbito local. Entre 1996 e 2002, foram promovidos diversos cursos de capacitação de conselheiros municipais, envolvendo formadores de Universidades, dos serviços públicos de extensão rural e de ONGs com atuação nas áreas rurais.

Para que um município se habilitasse, efetivamente, a receber os recursos do PRONAF Infra-estrutura, ele precisava seguir algumas etapas, resumidas por Lima Neto (2000) e reproduzidas a seguir:

a) levantamento das demandas dos agricultores familiares em obras e serviços públicos de apoio ao desenvolvimento;

b) elaboração do PMDR, com base nas demandas levantadas pelos agricultores familiares em suas comunidades;

c) análise do PMDR pelos diferentes fóruns responsáveis pela gestão do Programa: CMDR, Conselho Estadual e Secretaria Executiva Nacional do PRONAF;

d) elaboração anual do Plano de Trabalho (PT) no município a partir do PMDR;

e) aprovação do PT pelo CMDR e encaminhamento à Secretaria Executiva Estadual para emissão de parecer técnico;

f) análise do PT pelo Conselho Estadual;

g) análise e parecer conclusivo do PT pela Secretaria da Agricultura Familiar bem como aprovação pelo Ordenador de Despesas do PRONAF. 
h) encaminhamento do PT à Caixa Econômica Federal (CEF) para formalização do contrato com o Poder Executivo Municipal.

A atuação deste Banco junto ao PRONAF iniciou em 1997 e, em parte, pode ser explicada por se tratar do segundo banco público mais importante do país e porque o Banco do Brasil e o Banco do Nordeste atuam nas linhas de crédito para financiamento à produção do PRONAF. Contudo, a razão principal dessa escolha reside no fato de que a CEF é uma instituição que possui um corpo técnico que, há muito tempo, acompanha e fiscaliza obras e aquisição de equipamentos, sobretudo nos programas públicos de habitação. Na medida em que o PRONAF Infra-estrutura opera com esse tipo de ações, a contratação da CEF para realização do repasse de recursos e a sua fiscalização tornou-se funcional ao Programa.

A partir de novembro de 2001, começa a se esboçar uma reformulação no Programa no sentido de promover ações que não se limitem à esfera municipal. A Resolução $\mathrm{n}^{\circ} 27$ trouxe como novidade a previsão da utilização de 5 a $10 \%$ do valor da cota de cada estado para apoio a projetos de desenvolvimento rural e fortalecimento da agricultura familiar apresentados por organizações intermunicipais e a exclusão do programa dos municípios com mais de 100 mil habitantes. Previu-se, porém, uma regra de exceção para os municípios com população acima desse patamar desde que integrados em ações intermunicipais e que os demais municípios parceiros tivessem menos de 100 mil habitantes.

\section{As mudanças recentes e o desenvolvimento dos territórios rurais}

No entanto, a mudança mais recente e, quem sabe, a de maior impacto, se deu em 2003. Com a posse do novo Governo Federal, a estrutura do MDA foi reformulada, sendo criada a Secretaria de Desenvolvimento Territorial (SDT). Responsável pela gestão do PRONAF Infra-estrutura, a SDT passou a associar essa modalidade do programa à noção de "desenvolvimento territorial". Com isso, o município deixou de ser a unidade de referência dessa linha de crédito passando a beneficiar iniciativas intermunicipais. Segundo a própria SDT, na maior parte das vezes, o município isolado é uma unidade administrativa 
pouco adequada para gerir a rede de relações necessárias ao desenvolvimento rural. Nesse sentido, por meio de ações intermunicipais as organizações podem ampliar o raio de relações sociais dos agricultores familiares e dos assentamentos da reforma agrária. $\mathrm{Na}$ avaliação da SDT, o município seria uma instância decisiva de controle social, mas insuficiente para responder ao estímulo de uma proposta de desenvolvimento (SDT, 2003).

Em razão dessas limitações da esfera municipal, a nova Secretaria passou a atuar com base na idéia de territórios, entendo-se os territórios rurais como um espaço físico, geograficamente definido, geralmente contínuo, caracterizado por critérios multidimensionais que se relaciona interna e externamente por meio de processos específicos, onde se pode distinguir um ou mais elementos que indicam identidade e coesão social, cultural e territorial (MDA/SDT/CONDRAF, 2003) ${ }^{19}$.

A partir dessa nova unidade de referência o atual governo (iniciado em 2003) pretende mudar o enfoque das políticas públicas. Se antes os objetivos do programa eram mais centrados no provimento de infraestrutura agora deverão passar a atuar mais no fortalecimento da organização social dos agricultores familiares e estimular a participação das instituições de representação. Além disso, o novo formato prevê que as iniciativas locais e municipais se submetam a uma lógica de elaboração dos projetos a partir das demandas dos territórios em que estão inseridos ou a partir de agências ou instituições que já estejam formalmente constituídas na forma de consórcios ou associação.

De certo modo, este novo formato de atuação do programa vai de encontro a algumas recomendações que se faziam no sentido de evitar a excessiva pulverização dos investimentos em infraestrutura e serviços tomando-se como suporte e referência os municípios. Contudo, de outra parte, resta saber como os atores locais (prefeituras, cooperativas, sindicatos, associações, movimentos sociais, etc) vão reagir a esta nova

\footnotetext{
${ }^{19}$ A base teórica do enfoque territorial do desenvolvimento foi introduzido no Brasil por VEIGA, J. E. da. A face territorial do desenvolvimento. Anais... Belém, XXVII Encontro Nacional de Economia, 1999, p. 13011318. Quando da passagem desse autor pela coordenação do Conselho Nacional de Desenvolvimento Rural Sustentável elaborou o documento "O Brasil rural precisa de uma estratégia de desenvolvimento" (Brasília, CNDRS/MDA/NEAD, 2001, 107p.), onde explicita a necessidade das políticas públicas de desenvolvimento rural serem planejadas no âmbito intermunicipal.
}

\section{DOI: http://dx.doi.org/10.22295/grifos.v30i51.5656 | Edição - Vol. 30, Núm. 51, 2021.}

Este é um artigo publicado em acesso aberto (Open Access) sob a licença Creative Commons Attribution, que permite uso, distribuição e reprodução em qualquer meio, sem restrições desde que o trabalho original seja corretamente citado. 
proposição que pressupõem um mínimo de consenso, acordo e criação de uma estrutura de planejamento microrregional em torno das prioridades dos territórios.

Outra expectativa é com relação aos critérios para se efetuar a transição da gestão do programa. A nova lógica prevê que os "projetos de caráter regional serão apreciados e aprovados diretamente pelos Conselhos Estaduais". Assim, toda a ênfase dada anteriormente aos CMDR se enfraquece e esta instância tende a se tornar obsoleta. Neste sentido, cabe aguardar como a SDT procederá para habilitar as instituições a formular e a gerenciar os projetos intermunicipais bem como definir melhor qual será o papel dos CMDR nesse novo desenho institucional, uma vez que até então eles eram considerados o núcleo básico do Programa.

\section{CONSIDERAÇÕES FINAIS}

Este trabalho teve como objetivo fazer uma síntese do principal programa de apoio à agricultura familiar existente no Brasil, que é o Pronaf. Uma análise sobre sua trajetória recente indica que é um programa que está em evolução e em processo de aperfeiçoamento. Os avanços registrados pelo PRONAF nos últimos anos estão diretamente relacionados às mudanças implementadas no programa, tanto institucionais como financeiras, as quais deram maior capilaridade às diversas modalidades de crédito e tipos de financiamento aos agricultores familiares brasileiros.

Um dos aspectos centrais derivados dessa nova conjuntura é que o volume de recursos vem aumentando progressivamente desde 1997, o que significa uma possibilidade concreta de acesso ao crédito a um número maior de agricultores familiares, considerando os diferentes graus de inserção nos mercados e as distintas regiões do país. Desde a sua criação, o Programa tem sofrido constantes ajustes visando corrigir a forte concentração dos recursos do programa na região Sul do país verificada nos seus primeiros anos de existência. Nota-se que atualmente está havendo uma melhor distribuição dos recursos financeiros não somente entre as regiões brasileiras, mas também entre os diferentes níveis 
de renda dos agricultores familiares. Com isso, pode-se afirmar com segurança que o PRONAF se transformou em uma política pública de abrangência nacional.

Esse maior número de beneficiários também está relacionado às condições de financiamento que foram sendo melhoradas progressivamente. Hoje, a institucionalização de mecanismos compensatórios, a exemplo dos rebates e das taxas de juros fixas e abaixo das taxas praticadas pelo mercado financeiro, facilita o maior acesso aos recursos disponibilizados pelo programa.

No entanto, deve-se reconhecer que, mesmo com as mudanças implementadas na sistemática operacional do programa após 1999, ainda persistem algumas distorções que precisam ser continuamente corrigidas, como é o caso da elevada concentração dos recursos de custeio das safras nas duas categorias mais bem posicionadas da agricultura familiar, em detrimento das demais categorias geralmente em maiores dificuldades. Estes fatos, somados a outros de natureza estrutural, fazem com que o programa seja continuamente reformulado e repensado.

Em relação ao PRONAF infra-estrutura e serviços municipais, não é novidade para quem trabalha com o tema do desenvolvimento rural que a ampla maioria dos estados brasileiros não dispõe de fóruns regionais que se ocupem do planejamento e gestão do desenvolvimento. Dentre as exceções figuram os estados do Rio Grande do Sul, que desde 1994 possui os Conselhos Regionais de Desenvolvimento, e de Santa Catarina, que a partir de 2003 dispõem das Secretarias de Desenvolvimento Regional. Além disso, a capilaridade dos serviços públicos de extensão rural encontra-se, na atualidade, profundamente abalada, após quase duas décadas de enxugamento do seu quadro de funcionários. Mesmo naqueles estados onde se preservou uma estrutura mínima de funcionamento das empresas de assistência técnica e extensão rural, essas unidades restringem-se, quase que exclusivamente, a promover o desenvolvimento agrícola stricto sensu, dispondo de poucos profissionais capacitados a promover o desenvolvimento rural. Da mesma forma, o trabalho das ONGs, além de limitado do ponto de vista geográfico, se caracteriza pela dispersão, fragmentação e pontualidade, portanto ineficaz para gerir um programa com a envergadura e importância do PRONAF infra-estrutura e serviços municipais. 
O quadro atual dessa modalidade do Programa, afora as dúvidas de dirigentes municipais sobre como o mesmo será operacionalizado daqui para frente, passa a impressão de que acertaram aquelas administrações municipais que pouco apostaram nos conselhos municipais de desenvolvimento rural. A máxima que a cada novo governo tudo muda, justificando a precaução na adoção das orientações externas, mais uma vez se fez valer.

\section{REFERÊNCIAS}

ABRAMOVAY, R. Conselhos além dos limites. Revista Estudos Avançados. Dossiê Desenvolvimento Rural. São Paulo, USP, v. 15, n. 43, p. 121-141, set./dez. 2001.

ABRAMOVAY, R.; VEIGA, J. E. Novas Instituições para o Desenvolvimento Rural: o caso do Programa Nacional de Fortalecimento da Agricultura Familiar (PRONAF). Texto para Discussão No 641 (Convênio FIPE/IPEA 07/97). Brasília: IPEA, abr./1999.

\section{ABRAMOVAY, R. Relatório Institucional da Secretaria da Agricultura Familiar.} Brasília: PNUD, Projeto BRA-98/012, jun./2002. (Relatório de Pesquisa).

BELIK, W. PRONAF: uma avaliação da operacionalização do programa. In: CAMPANHOLA, C.; GRAZIANO DA SILVA, J. (Eds.). O Novo Rural Brasileiro: Políticas Públicas. Jaguariúna: Embrapa Meio Ambiente/IE/UNCIAMP, 2000. p. 93-116. (Volume 4).

BITTENCOURT, G. A. Cooperativas de crédito solidário: constituição e funcionamento. 2. ed. Brasília, NEAD, 2001. 143p.

BURIGO, F. L. Cooperativa de crédito rural: agente de desenvolvimento local ou banco comercial de pequeno porte? Florianópolis, PPGAGR/UFSC, Dissertação de Mestrado, 1999. 114p.

CARVALHO FILHO, J. J. Política agrária do governo FHC: desenvolvimento rural e nova reforma agrária. In: LEITE, S. (Org.). Políticas Públicas e Agricultura no Brasil. Porto Alegre: Editora da UFRGS, 2001.

CAZELLA, A. A. Cooperativismo de crédito rural: lições de uma experiência. In: MONTOYA, M. A. (Org.). Aspectos regionais do crédito rural: governo, cooperativas e informalidade. Passo Fundo: Ed. UPF, 2002. p. 25-46.

CAZELlA, A. A.; MATTEI, L.; DELGADO, N. G. A gestão do PRONAF Infraestrutura e Serviços pelos Conselhos Municipais de Desenvolvimento Rural: evidências 
sobre o Estado de Santa Catarina. In: Anais do XL Congresso da SOBER, Passo Fundo, 2002. 16p.

DENARDI, R. Relatório executivo dos cursos para conselheiros municipais de desenvolvimento rural realizados nos anos de 1998 a 2000. Paraná: EMATER/DESER, 1999 (mimeo).

DENARDI, R. et al. Fatores que afetam o desenvolvimento local em pequenos municípios do Estado do Paraná. Curitiba: EMATER, 2000.

EMATER/Paraná. Fatores que afetam o desenvolvimento local em pequenos municípios do Estado do Paraná. Curitiba: EMATER, 2000.

FAO/INCRA. Diretrizes de política agrária e desenvolvimento sustentável para a pequena produção familiar. Brasília, 1994a. 98p.

FAO/INCRA. Diretrizes de política agrária e desenvolvimento. Brasília, versão resumida do relatório final do projeto UTF/BRA/036, 1994b. 24p.

FERREIRA, B.; SILVEIRA, F. G.; GARCIA, R. C. A agricultura familiar e o PRONAF: contexto e perspectivas. In: GASQUES, J. G.; CONCEIÇÃO, J. C. P. R. (Orgs.).

Transformações da Agricultura e Políticas Públicas. Brasília: IPEA, 2001. p. 479-539.

GUANZIROLI, C. H.; CARDIM, S. E. (Coords.). Novo Retrato da Agricultura Familiar: o Brasil redescoberto. Projeto de Cooperação Técnica INCRA/FAO. Brasília, fev./2000.

IBASE. Avaliação de Planos Municipais de Desenvolvimento Rural - PMDRS em quatro Estados: ES, MS, PE, SC. 2001.

IBASE. Avaliação do PROGER, PROGER RURAL e PRONAF do Fundo de Amparo ao Trabalhador - FAT. Ministério do Trabalho/IBASE (Contrato MTb/Codefat $\mathbf{n}^{\mathbf{0}}$ 002/98). RELATÓRIO GERAL, Tomos I e II. Brasília, jun./1999.

IPARDES/Paraná. Caracterização dos Conselhos Municipais de Desenvolvimento Rural do Paraná: síntese dos principais resultados da pesquisa de campo. Curitiba: IPARDES, 2001. 27p.

JORNAL DA AGRICULTURA FAMILIAR. Brasília: MDA, 2003.

LIMA NETO, P. C. PRONAF Infra-Estrutura e Serviços Públicos Municipais: Histórico e Perspectivas para o ano 2000. Brasília: MDA/SAF, 2000. (mimeo). 
MATTEI, L. Programa Nacional de Fortalecimento da Agricultura Familiar: balanço e perspectivas. UFSC/Economia: Texto para Discussão $\mathrm{n}^{\circ}$ 05, 2001.

MDA/SDT/CONDRAF. Referências para um programa territorial de desenvolvimento rural sustentável. Brasília: CONDRAF/NEAD, Texto para Discussão nº 04, 2003.

MINISTÉRIO DO TRABALHO. Avaliação do PROGER, PROGER RURAL e PRONAF. IBASE, Relatório Geral e Relatório Final dos Estados - CD-ROM, jun./1999.

PICINATTO, A. G. et al. Cartilha do PRONAF Crédito. Curitiba: DESER (Departamento de Estudos Sócio-Econômicos Rurais), 2000.

SABBATO, A. D. O público-alvo do crédito rural do PRONAF: estimativa a partir dos dados do Censo Agropecuário do IBGE de 1995-1996. Projeto Incra/FAO, Brasília, set./2000 (mimeo).

SCHNEIDER, S. Avaliação da experiência de capacitação dos conselheiros dos CMDRs no Estado do Rio Grande do Sul. Nota técnica para o projeto

PNUD/BRA/98/012. UFRGS-Fundação Lindolfo Silva, Porto Alegre, 2001 (mimeo).

SDT. Infra-estrutura e serviços municipais: em apoio ao desenvolvimento territorial. Brasília, SDT/MDA, 2003.

VEIGA, J. E. da. A face territorial do desenvolvimento. Anais do XXVII Encontro Nacional de Economia, Belém/PA, 1999. p. 1301-1318.

VEIGA, J. E. da et al. O Brasil rural precisa de uma estratégia de desenvolvimento. Brasília: CNDRS/MDA/NEAD, 2001. 107p.

VEIGA, J. E.; ABRAMOVAY, R. Análise (diagnóstico) da inserção do PRONAF na política agrícola: primeiro relatório. São Paulo, Convênio IPEA/FIPE nº 07/97, 1997. 30p. 